\title{
La pax y la lex humana en la obra de Marsilio de Padua: ¿una lectura inédita sobre el origen de la comunidad política?
}

(1) Antonio Sparano

Universidad de Buenos Aires, Argentina.

Recibido el 22/08/2018; aceptado el 23/11/2018.

\begin{abstract}
Resumen
El trabajo analiza la concepción de la paz en el pensamiento de Marsilio de Padua a partir de la noción de ley que desarrolla en el Defensor Pacis. Para poner en evidencia la novedad introducida por Marsilio, compara su teoría de la ley con las teorías de la ley de Aristóteles y Tomás de Aquino
\end{abstract}

Peace and human law in Marsilius de Padua's work: an unprecedented interpretation about the inception of the state?

\begin{abstract}
The paper deals with the concept of peace in Marsilius de Padua's thought based on the notion of law that he develops in the Defensor Pacis. In order to show the novelty introduced by Marsilio, the paper compares his theory of law with the theories of law of Aristotle and Thomas Aquinas.
\end{abstract}

En la tradición jurídica y política medieval, la paz fue siempre concebida como una convivencia ordenada, es decir, inspirada en los principios de una ética superior a la reglamentación positiva. El binomio derecho-paz se basaba en una concepción de lex naturalis cuyas proyecciones metafísicas y teológicas desempeñaban un papel decisivo en la constitución y conservación de la comunidad política. Esto, así como la superioridad de la ley sobre el soberano, se puede notar en muchos tratados políticos de la época. Es la primacía de la ley, no la del rey, la que garantiza la paz. El rey es elegido para que garantice la justicia a todos, es decir, como resalta Juan de Salisbury, haga siempre lo que la ley y la justicia permiten y lo que sugiere la razón común, y no actúe nunca según su propia voluntad (Policraticus, 2 vol., IV, 1).

En este ámbito, Marsilio de Padua marca una ruptura con la tradición anterior, incluso con la tomista. Para el patavino, la paz es paz civil, fruto de la civitas: necesidad

\section{Palabras clave}

Defensor Pacis ley paz universitas civium vita sufficiens

\section{Keywords}

Defensor Pacis law peace universitas civium vita sufficiens 
1. Aquí y en todas las citas de Defensor Pacis a lo largo del artículo sigo la traducción al español de Luis Martínez Gómez (1989).

2. Piénsese, en particular, en el género de los specula principis. biológica que se convierte en necesidad política. En Defensor Pacis (DP), la pax no se configura como una dimensión ético-espiritual, ni como una condición vinculada al destino ultramundano de los individuos (Agustín de Hipona, De Civitate Dei, XIX, 12), sino como una relación armoniosa entre los individuos en la politia, al punto de constituir una relación de circularidad con la ley positiva, de la que es, al mismo tiempo, origen y consecuencia (De Lagarde, 1970: 66 y ss). La paz no es el objetivo final de la actividad política, sino el medio básico para construir una vita sufficiens: esta, en efecto, deriva del funcionamiento no conflictivo [pax, de hecho] de la organización civil, o más bien, del correcto cumplimiento de las diversas funciones del estado.

Marsilio observa que, al igual que la salud del cuerpo, incluso la paz del estado depende de la posibilidad total de cada una de sus partes de "facere perfecte operaciones convenientes sibi secundum racionem et suam institucionem" [puede realizar las operaciones convenientes a su naturaleza según la razón y su institución $]^{1}$ $(D P, \mathrm{I}, \mathrm{II}, 3)$. Por otro lado, la ausencia de paz en la política corresponde a una mala disposición de sus partes, al igual que la enfermedad de un organismo implica que "impediuntur omnes aut alique partes illius facere opera sibi conveniencia, simpliciter vel in complemento" [están impedidos todos o algunos de sus miembros para hacer su operaciones propias, o tomados aparte absolutamente, o en su 'conjunto y funcionamiento total] ( $D P$, I, II, 3). En este sentido, la búsqueda de la paz no puede ser solo prerrogativa del soberano, como en los tratados políticos anteriores, ${ }^{2}$ según los cuáles la virtud del soberano, entendida en el sentido platónico y cristiano como la facultad ordenadora del alma, era la única capaz de darle, en primer lugar, al mismo rey y, luego, al pueblo, normas éticas superiores, sino que tiene que ser una predisposición a la vita sufficiens o’, más bien, a la composición tranquila de los intereses, que va a pertenecer a la universitas civium, es decir, a todo el cuerpo de ciudadanos.

Sin embargo, esta relativización del significado moral de la pax también puede verse con respecto a la ley: para el patavino, la lex ya no es opus virtutis, sino el discernimiento de lo útil de lo dañino; y esto rehabilita constitutivamente al populus seu eius valentior pars a hacerse legítimamente cargo de ella. En el Defensor Pacis, la indagación de aquello que en la esfera política debe tener el valor de ley es considerablemente diferente respecto de la praxis tradicional, como la expuesta por Tomás de Aquino. El patavino distingue, al comienzo de la obra, todas las acciones en actus imperati ed actus non imperati, según sean causadas o no por las determinaciones del intelecto; luego, fija su atención en los primeros: estos pueden ser immanentes o transeuntes. Inmanentes son aquellos pensamientos o deseos que permanecen en la esfera del sujeto agente; transeúntes son todos los movimientos del cuerpo y del alma que tienen una manifestación objetiva en una persona diferente del agente $(D, \mathrm{I}, \mathrm{V}, 4)$. Los actus imperati son objeto de una disciplina que implica la perspectiva de una retribución en términos de penalización o recompensa; y es sobre esta constatación que se articula su teoría del derecho. Esta retribución, de hecho, puede realizarse en este mundo o en el otro; de aquí la distinción entre la lexhumana y la lex divina y la consiguiente restricción de la esfera del derecho respecto a la de la moral.

Para Marsilio de Padua, la ley divina [la norma moral-religiosa] se refiere a los actus humani imperati immanentes et transeuntes, es decir, que tanto los actos internos como los externos pueden ser regulados jurídicamente. Sin embargo, si la ley divina refleja un espectro más amplio de acciones, ella se manifiesta solo en la vida futura, por lo que carece de la coacción, podríamos decir, mundana, que atañe al precepto jurídico positivo. De hecho -argumenta Marsilio- la ley, en su sentido más apropiado, no es solo una regla coactiva -por la que toda transgresión debe ser castigada 
por un poder otorgado a quien debe juzgar de acuerdo con esa misma ley-, sino que esta coacción debe ser actual (DP, I, X, 4). La ley y el legislador evangélico, en cambio, no pueden obligar a nadie a su acatamiento en este mundo, por lo que, con respecto a su relación con el estado del hombre en la actualidad, es preciso llamarla doctrina y no ley.

Como puede verse, el alejamiento de la tradición tomista es evidente. Para Tomás, el punto de partida de la investigación sobre la ley es la lex aeterna, razón de la sabiduría divina, relativa a cada movimiento: plan del intelecto divino según el cual todo está dirigido a su fin último. Cualquier criatura racional, dice el aquinate, "ipsam cognoscit secundum aliquam eius irradationem, vel maiorem vel minorem" [conoce algo según la claridad de su manifestación, o mayor o menor] ${ }^{3}$ (Summa Theologiae, I, II, q. 93, a. 2.). Este conocimiento, que se puede encontrar en diferentes grados, según la capacidad de cada uno, traza el recorrido de la lex naturalis como participatio legis aeternae in rationali creatura [la participación de la ley eterna en la creatura racional] (Summa Theologiae, I, II, q. 91, a. 2). Cuando, finalmente, el dominico pasa a enunciar la definición de ley positiva como ordinatio rationis ad bonum commune ab eo qui curam communitatis habet promulgata [un mandato de la razón en orden al bien común, promulgado por aquel que tiene a cargo el cuidado de la comunidad] (Summa Theologiae, I, II, q. 90, a. 4), toma las categorías de fin, de razón y, por supuesto, de lex naturalis, en un diseño unitario conceptualmente necesario. En Tomás, la relación entre la ley natural y la positiva es central, ya que vincula el valor de la norma a su contenido de justicia ex lege naturali. En efecto, dice el aquinate:

\begin{abstract}
Y tratándose de cosas humanas, su justicia está en proporción con su conformidad a la norma de la razón. Pues bien, la primera norma de la razón es la ley natural, como consta por lo ya dicho. Por consiguiente toda ley humana tendrá carácter de ley en la medida en que se derive de la ley de la naturaleza; y si se aparta en un punto de la ley natural, ya no será ley, sino corrupción de la ley (Summa Theologiae, I, II, q. 95, a. 2). ${ }^{4}$
\end{abstract}

Entonces, para Tomás, la ley humana tiene un doble aspecto: es un medio ordenado para un fin, que es el bien del hombre, y es una regla medida por un criterio superior, ofrecido por la lex divina y la lex naturalis.

Marsilio, en cambio, desde el principio, plantea su propio discurso sobre los orígenes de la ley a partir de la idea de una retribución-sanción, evitando enfrentarse con la más compleja partición tomista [lexaeterna, divina, naturalis, humana]: en su doctrina la materialidad de la ley es central. Partiendo de Aristóteles, el patavino afirma que la ley es "un enunciado, pues, o proposición procedente de una prudencia e inteligencia, política, se entiende; o también, una ordenación sobre lo justo y lo conveniente y sus opuestos, según la prudencia política" $(D P, \mathrm{I}, \mathrm{X}, 4){ }^{5}$; pero luego agrega que:

[...] no todos los conocimientos verdaderos de lo justo y lo conveniente civil son leyes si no hay de ello un precepto coactivo o no se dieran por modo de precepto, si bien ese conocimiento verdadero necesariamente se requiere para la ley perfecta. Mas aún, a veces se dan por leyes falsas ideas de lo justo y útil cuando de ellas se da precepto de observancia o se dictan por modo de precepto $(D P, I, X, 4){ }^{6}$

Entonces, por dignidad también una ley imperfecta es lex, ya que la justicia material de su contenido no es una prerrogativa de la ley en sí misma inspirada en la lex naturalis, sino que deriva del poder del legislador humano. En la concepción del patavino, el bien común no depende de una presunta ley justa, sino de la libre voluntad humana, de la que es expresión la estructura legislativa de la civitas,
3. Aquí y en otros pasajes ofrezco una traducción propia del latín; en adelante señalo en nota al pie únicamente los casos en que sigo otras traducciones.
4. Sigo en este pasaje de Summa Theologiae la traducción de la edición de la Biblioteca de Autores Cristianos (1967). El pasaje en latín: "In rebus autem humanis dicitur esse aliquid iustum ex eo quod est rectum secundum regulam rationis. Rationis autem prima regula est lex naturae. Unde omnis lex humanitus posita intantum habet de ratione legis, inquantum a lege naturae derivatur. $\mathrm{Si}$ vero in aliquo a lege naturali discordet, iam non erit lex, sed legis corruptio"(Summa Theologiae,I, II, q. 95, a. 2).
5. El pasaje en latín: "ens ab aliqua prudencia et intellectu; sermo igitur seu oracio ab aliqua prudencia seu intellectu, politico scilicet, id est ordinacio de iustis et conferentibus et ipsorum oppositis per prudenciam politicam" $(D P, I, X, 4)$.
6. El pasaje en latín es el siguiente: "iustorum et conferencium civilium non omnes vere cogniciones sunt leges, nisi de ipsarum observacione datum fuerit preceptum coactivum, seu late fuerint per modum precepti, licet talis vera cognicio ipsorum necessario riquiratur ad legem perfectam. Quinimo quandoque false cogniciones iustorum et conferencium leges fiunt, cum de ipsis datur observacionis preceptum, seu feruntur per modum precepti" $(D P, I, X, 4)$. 
7. El pasaje en latín: "populum seu civium universitatem aut eius valenciorem partem, per suam eleccionem seu voluntatem in generali civium congregacione per sermonem expressam precipientem seu determinatem aliquid fieri vel omitti circa civiles actus humanos sub pena vel supplicio temporali" $(D P, \mathrm{I}, \mathrm{XII}, 3)$. es decir, de la primacía del legislador justo. La única concesión que Marsilio de Padua está dispuesto a hacer con respecto a la relación ley-naturaleza es legitimar la antigua máxima quod omnes tangit ab omnibus approbari debet, pero siempre en vista de la centralidad del legislador, o sea, del populus: ya que es natural que para sí mismo este desee las normas mejores, y que no haya nadie más que el pueblo entero que pueda juzgar con más cognición la idoneidad de los medios elegidos para vivir bien.

Con Marsilio, el derecho natural abandona cualquier función de regulación del derecho positivo para convertirse en el momento de emergencia de la autoridad humana que, legislando, modela o, mejor dicho, da sustancia y contenido a la ley. En el sistema concebido por Marsilio ya no se da ninguna ley axiomáticamente buena, sino solo un legislador constitutivamente justo que produce normas imperativas igualmente justas. Este, como hemos dicho, es

el pueblo, o sea la totalidad de los ciudadanos o la parte prevalente de él, por su elección y voluntad expresada de palabra en la asamblea general de los ciudadanos, imponiendo o determinando algo que hacer $\mathrm{u}$ omitir acerca de los actos humanos civiles bajo pena o castigo temporal $(D P, I, X I I, 3){ }^{7}$

Esta definición implica algunos elementos fundamentales de la configuración constitucional elaborada por el patavino, como el populus, la pars valentior [parte preponderante], y sobre todo la lex [el legislador se presenta como su primera causa eficiente], que aparece como una noción guía, capaz de iluminar a todas las demás. De hecho, no es posible ignorar su significado de obligación relativo a las acciones civiles humanas, bajo la amenaza de una pena o castigo temporal, que es precisamente su significado específico, bien distinto de los otros significados enumerados por Marsilio, en los que la ley se presenta como un simple conocimiento o criterio para la evaluación de lo justo e injusto $(D P, \mathrm{I}, \mathrm{X}, 5)$, es decir, como una doctrina. Es a esta función imperativa de la lex a la que se vincula la necesidad de conferir el poder legislativo a toda la universitas civium. Para el patavino, la lex no es la aplicación de la ciencia de lo que es justo y civilmente ventajoso, porque en tal caso para ponerla en práctica bien bastarían, entre los ciudadanos, los que son más ancianos y, sobre todo, más expertos en los asuntos prácticos, a saber, los prudentes (DP, I, XII, 2); pero dado que sin el precepto coactivo de quien, con legítima autoridad, obliga a la observancia o castiga a los transgresores esta ciencia aún no es ley, su autor solo puede ser todo el cuerpo de los ciudadanos [universitas civium]. A la base de la tesis del patavino está la creencia de que la mejor ley es la que se hace para la ventaja común de los ciudadanos, la cual se puede ver con más evidencia cuanto mayor sea el número de sujetos involucrados. En otras palabras, Marsilio toma prestado el principio aristotélico de la superioridad del todo sobre la parte (Aristóteles, Pol. 1281a, 40 y ss), del cual deduce necesariamente que la universitas civium puede discernir lo que debe elegirse o debe rechazarse mejor que cada una de sus partes considerada separadamente ( $D P$, IXIII, 2). Además, si es cierto que, como dice el estagirita, el estado es una comunidad de hombres libres (Aristóteles, Pol. 1279a, 21), entonces "aquella ley mejor se cumple por cualquiera de los ciudadanos que parece ser la que cada cual se ha impuesto a sí mismo" (Marsilio de Padua, DP, I, XII, 6); lo que ciertamente no ocurriría si solo uno o unos pocos ciudadanos legislaran para todo el pueblo, ya que una norma impuesta oligárquicamente, "quantumcumque bonam" ( $D P$, I, XII, 6), podría ser mal tolerada por el resto de los ciudadanos, es decir, sufrida como si fuera una afrenta, y, por lo tanto, no observada. En cambio, una ley hecha mediante la escucha y el consentimiento de toda la multitud, incluso si fuera menos útil, sería fácilmente observada y apoyada por todos los ciudadanos, "[...] porque es como si cada cual se la hubiera dado a sí mismo y por ello no le queda gana de protestar contra ella" (DP, I, XII, 6). 


\section{Conclusiones}

Será preciso, para concluir este recorrido de lectura que propongo, hacer algunas breves aclaraciones sobre la relación entre el pensamiento de Marsilio y las ideas políticas de Aristóteles. Como ya se ha señalado en otras ocasiones (Sparano, 2017: cap. 10), no puede considerarse plausible la tesis de una fidelidad sustancial del patavino al espíritu de la Política, y, en consecuencia, subestimar el alcance innovador de sus tesis sobre el origen de la lex y, más en general, de toda su teoría del estado, reduciéndola solo al ámbito de la tradición aristotélica medieval.

Centrándose en el principio aristotélico que acabamos de mencionar, para el que el todo es superior a la parte, es posible afirmar que en la obra del estagirita este principio goza de un apoyo ético mucho más sólido que en el Defensor Pacis, en el que también se adopta con convicción. En la Política, la transición de la familia a la aldea y luego al estado es un proceso teleológico, que va de la procreación a la seguridad, del desarrollo de las cualidades personales a la autosuficiencia y la vida virtuosa. La doctrina política de Marsilio carece de ese proceso de evolución rígido y, por lo tanto, hace posible pensar a la participación del pueblo [es decir, de todos los ciudadanos], que para el estagirita ya correspondería a una fórmula de régimen ${ }^{8}$ [la politeia y/o la democracia], como condición para el surgimiento de la comunidad política. Según el patavino, que el hombre se organice políticamente no significa que sea sociable por naturaleza, sino que lo es por una necesidad biológica-económica; su naturaleza no tiene que perfeccionarse en la civitas, sino solo moderarse y realizarse, y esto depende del comportamiento de todos: del gobernante, como para Aristóteles y gran parte de la tradición filosófica anterior, pero también de los gobernados, afirma Marsilio.

En el Defensor Pacis, el criterio de distinción entre las formas de gobierno templadas y viciadas es doble, ya que está constituido por el recto interés de los que gobiernan, pero también por la voluntad de quien es gobernado; mientras que la posición de Aristóteles (Pol. 1279a y ss) identifica la diferencia en el criterio único del ejercicio, honesto o ímprobo, del poder por parte del gobernante. Y lo mismo vale para Tomás de Aquino: la monarquía, dice en Summa Theologiae, es el dominio de uno solo, ejercido honestamente; la aristocracia, el gobierno honesto de unos pocos; en la forma mixta, uno solo prevalece sobre los otros por su honradez, mientras que bajo él presiden otros hombres eminentes por virtud (Summa Theologiae, I, II, q. 90, a. 3). En Marsilio hay, como se ha visto, una referencia al interés general, pero sobre todo a la voluntad y al consentimiento de los ciudadanos. De esta manera, el magister patavino reduce la relevancia de la virtud y la honestidad, propia de toda la tradición política y filosófica precedente, y parece anticipar, de alguna manera, un tema que luego se desarrollará en la edad moderna, es decir: la separación entre la cuestión relacionada con las formas de gobierno como momento técnico de ejercicio del poder, y la relacionada con la titularidad de la soberanía, que, en cambio, pertenece al legislator humanus, o sea, a todos los ciudadanos.
8. Es decir: que se refiere a la actividad de gobierno. 


\section{Bibliografía}

" Agustín de Hipona (1992). De Civitate Dei. C. Carena (ed.). Torino: Einaudi.

" Aristóteles (2002). Política (trad. y notas de Augusto Viano). Milano: BUR.

»De Lagarde, G. (1970). La naissance de l'esprit laïque ou déclin du moyen age. III. Le defensor pacis. Louvain-Paris: Nauwelaerts.

» Juan de Salisbury (1964). Policraticus. C. J. Webb (ed.). Frankfurt.

" Marsilio de Padua (2001). Defensor Pacis (intro.de Mt. Fumagalli Beonio Brocchieri, trad. y notas de M. Conetti, C. Fiocchi, S. Radice, S. Simonetta). Milano: BUR.

" Marsilio de Padua (1989). El Defensor de la Paz (estudio, traducción y notas de Luis Martínez Gómez). Madrid: Tecnos.

"Sparano, A. (2017). Dall'Ayaษóv alla vita sufficiens (Declino e rinascita del dialogo politico). Roma: Aracne Editrice.

" Tomás de Aquino (1966). Summa Theologiae (trad. y comentario: Dominicos Italianos). San Casciano: Casa Editrice Adriano Salani.

"Tomás de Aquino (1967). Suma de Teología. Madrid: BAC. 